\title{
Discussions on Exchange Rate Behavior per Duration
}

\author{
MYoung SHIK CHOI*
}

\begin{abstract}
In foreign exchange transaction, arbitrage mechanism is the means by which a market functions with the global market order. An arbitrage confirms that bilateral exchange rate is the same as trilateral rates. However, the long-run behavior of the exchange rate could be diverged from the short-run movement. This study, in this sense, reviews the advances of exchange rates in the long-run and the short-run respectively in order to develop desirable attainments on their optimality conditions. These effects on the economy will be discussed. In concluding words, it is revealed that the short-run and the long-run exchange rates exhibit a significant discrepancy and have different behaviors. This implies that any spread between the short-run and the long-run exchange rates might happen due to partially different adjustment of the arbitrage rule.
\end{abstract}

Keywords: Exchange Rate Arbitrage, Interdealer Market, Surprising, Volatility

JEL: F31, F37, F41

Myoung Shik Choi, Research Professor, Department of Economics, Sungkyunkwan University, Seoul, 110-745, Korea; Tel: +82-10-8408-7373; E-mail: msc50355@skku.edu 


\section{INTRODUCTION}

There are slightly more than 200 types of currencies. Foreign currency 1 exchanges involve relative exchange prices since countries have their own currency. Foreign exchange trades operate tick-by-tick in a decentralized global market that is open 24 hours a day, 7 days a week. Although dealers are geographically separated from one another, they use electronic media such as email, telephones, and the dealing screen system in order to make their currency transactions. ${ }^{1}$ Indeed, the foreign exchange volumes between dealers constitute the largest transactions. Thus, dealers are considered as market makers or leverage speculators.

Most foreign exchange rates fluctuate. This fickle jumpiness in exchange rates might be a result of the existence of an un-equalized distribution of currency trading prices. Generally, among foreign exchange trading participants, dealers are international mercantile banks while non-bank customers are exporters, importers and multinational corporations. Transactions between dealers are referred to as inter-dealer transactions. Dealers locally have transactions with domestic customers. Therefore, heterogeneous decisions made by the corporate customers or dealers cause the quoted exchange rate to be amiss.

Following the breakdown of the Bretton Woods system, the foreign exchange market became more transparent than ever, but still remains to be opaque. ${ }^{2}$ Macro-fundamentals approach would determine the exchange rate movement over a longer time horizon. In recent micro-structure models, empirical approach can capture the short-run trend and drift of the exchange rate in terms of news, sterilization, technical charts, and irrational expectation. The, the microstructure approach would be capable of explaining the short-term exchange rate behavior by the market structures and the experience of the participants. Hence, we need to review the entire bodies of long-run exchange rates on the macro-fundamentals and short-run exchange rates based on micro-foundations. Meanwhile, we may suggest a short run exchange rate like a transit fickle price indirectly.

In other words, exchange rate movements will appear to be closely correlated with macroeconomic variables, participant actions, and market structures. However, these correlations are probably more complicated than one would anticipate. In order to disentangle the intertwined problems, this article will specify the exchange rate behavior per duration through a literature survey. Then, we can provide a testable optimality condition for the exchange rate behavior in the reality of the foreign exchange market. Especially, the distinction between this study and the previous literatures could be specified as our claim on the possibility of partially different adjustment of the arbitrage mechanism between the long-run and the short-run durations. 


\section{LONG-RUN FOREIGN EXCHANGE RATE}

In order to search for a standard form of the exchange rate model in the long run, we begin with a monetary approach explained by Levich (1985). The domestic real money demand $(\mathrm{M} / \mathrm{P})$ is explicitly represented as $\mathrm{M} / \mathrm{P}=$ $\mathrm{K} \cdot \mathrm{Y}^{n} \cdot \exp ^{-\varepsilon i}$ where $\mathrm{M}$ represents the stock of money, $\mathrm{P}$ refers to the price level of goods and services produced, $\mathrm{Y}$ is the real income, $\mathrm{i}$ is the interest rate, $\mathrm{K}$ represents other factors such as the value of the expected inflation rate, $\eta$ is the real income-elasticity of the money demand, and $\varepsilon$ is the approximate interest rate-elasticity of the money demand. Also, it is assumed that the money demand $(\mathrm{M} / \mathrm{P})$ is positively correlated with a general level of real economic activity (Y), and negatively correlated with an opportunity cost (i). For simplicity, if both nations are assumed to have identical elasticity, then the real money demand in the foreign country $\left(\mathrm{M}^{*} / \mathrm{P}^{*}\right)$ is specified as $\mathrm{M} * / \mathrm{P}^{*}=\mathrm{K}^{*} \cdot \mathrm{Y}^{*^{n}} \cdot \exp ^{-\varepsilon^{*}}$

When purchasing power parity, $\mathrm{S}=\mathrm{P} / \mathrm{P}^{*}$ is holding, the monetary linear equation can be expressed as $\mathrm{S}=\left(\mathrm{K}^{*} / \mathrm{K}\right) \cdot\left(\mathrm{M} / \mathrm{M}^{*}\right) \cdot\left(\mathrm{Y}^{*} / \mathrm{Y}\right)^{\mathrm{n}} \cdot \exp ^{\varepsilon\left(\mathrm{i}-\mathrm{i}^{*}\right)}$, where $\mathrm{S}$ is the spot exchange rate. Thus, the exchange rate model is obtained by taking natural logarithms of the equation in the following,

$$
s=\left(k^{*}-k\right)+(m-m *)+n(y *-y)+\varepsilon(i-i *)
$$

In this equation, $s$ refers to exchange rate. Each lowercase letter indicates the logarithm of their respective capital letter. Note that this linear equation is a type of modern monetary model. The monetary model emphasizes a financial asset market with the assumption of perfect bond substitutes as well as perfect international capital mobility. Also, an additional assumption of a stable demand for money implies that the relationships among money demand, income, and price do not alter significantly. 3

Furthermore, the preferences regarding global currency are expected to affect the exchange rate movement as reflected in the currency portfolio balance of the residents in a nation. Currency substitution from currencies that have experienced high inflation to low inflation types of currencies allows foreign residents to hold the domestic currency and vice versa. Currency substitution and complementarities depend upon the international currency dependency or independency. Kingston and Melecky (2007) suggest that the currency substitution or complementarities can lessen the exchange rate volatility. The currency substitution is an important factor that determines exchange rate as He and Sharma (1997) and other economists mention.

An extension of equation (1) allows prefect currency substitution in cases such as the dollarization in many Latin American countries. Then, it is assumed that the domestic demand for money is consisted of a portion of domestic residents, $\lambda$, and the other parts from abroad, (1- $\lambda)$, while the foreign money demand 
belongs to a part of the foreign residents, $\lambda^{*}$, and the others from abroad, $\left(1-\lambda^{*}\right)$. In this case, $\mathrm{m}=\lambda \mathrm{m}+(1-\lambda) \mathrm{m}$ and $\mathrm{m} *=\lambda^{*} \mathrm{~m} *+(1-\lambda *) \mathrm{m}^{*}$, where $\lambda=\lambda^{*}=1$ when all of the residents exclusively demand their local money. Additionally, we can intuitively predict that the currency substitutes will require a rise in the real quantity of the domestic currency by increasing the foreign interest rate, while the currency complements will be required to decrease the domestic currency demand, which will cause an increase of the foreign interest rates. Therefore, the currency substitutions or complementarities may be represented by the cross-elasticity of the money demand with respect to the foreign interest rates.

Let the equation (1) apply to the world economy consisting of two countries, in which the real demands for money are attained by the domestic and foreign residents.

$$
s=\left(k^{*}-\mathrm{k}\right)+\lambda\left(\mathrm{m}-\mathrm{m}^{*}\right)+(1-\lambda)\left(\mathrm{m}-\mathrm{m}^{*}\right)+n\left(\mathrm{y}^{*}-\mathrm{y}\right)+\varepsilon(\mathrm{i}-\mathrm{i} *)
$$

Where equation (1) is identical to equation (2) except for the term of weighted average parameter, $\lambda$. The macroeconomic fundamentals in parentheses indicate that $\left(\mathrm{y}^{*}-\mathrm{y}\right)$ is equal to the production differential, $\left(\mathrm{i}-\mathrm{i}^{*}\right)$ means the interest rate discrepancy, and $\left(\mathrm{k}^{*}-\mathrm{k}\right)$ represents the inflation or the expected inflation differential. Particularly, $\lambda\left(\mathrm{m}-\mathrm{m}^{*}\right)$ represents the money demand differential that is held by domestic residents and $(1-\lambda)\left(m-m^{*}\right)$ is the differential that is owned by foreign residents. The additional simple exposition can be assumed so that $\lambda$ equals $\lambda^{*}$.

Another extension would allow risk-averse agents to adjust their portfolio investment. Investors prefer diversifying their international assets to avoid foreign exchange risks on foreign currency-denominated bonds. ${ }^{4}$ The portfolio balance approach realistically adopts imperfect substitutes. That is the reason why the risk premium on the domestic bonds increases in the manner the domestic currency depreciates when the supply of the domestic bonds is greater than the supply of the foreign bonds. The risk premium leads to the breakdown of the uncovered interest rate parity condition (UIRP). The logarithm containing the UIRP corresponds to the differential between the domestic and the foreign returns, $\left[\mathrm{i}-\left(\mathrm{s}^{\mathrm{e}}-\mathrm{s}\right)-\mathrm{i}^{*}=\mathrm{rp}\right]$, where $s^{\mathrm{e}}$ is the expected exchange rate and $\mathrm{rp}$ is the risk premium. A positive risk premium would come out to the domestic currency if the effective return differential is positive.

Hence, the exchange rate equation can be re-written by the following equation:

$$
s=1 /(1+\varepsilon) Z_{1}+\varepsilon /(1+\varepsilon)\left(s^{e}+r p\right)
$$

$Z_{1}$ is a reduced form of $\left\{\left(k^{*}-k\right)+\lambda\left(m-m^{*}\right)+(1-\lambda)\left(m-m^{*}\right)+n\left(y^{*}-y\right)\right\}$. Note that an increase in an expected exchange rate or a risk premium will result 
in a depreciation of domestic currency if all other variables remain constant. If agents use the forward exchange contracts to eliminate the exchange risk, then the covered interest rate parity condition (CIRP) with logarithm can hold as $[\mathrm{i}-\mathrm{i} *=\mathrm{f}-\mathrm{s}$ ], where $\mathrm{f}$ indicates the forward rate and ( $\mathrm{f}-\mathrm{s})$ refers to the forward premium. The positive risk premium is when the current forward rate is bigger than the expected future spot rate such that $\left[\mathrm{rp}=\mathrm{f}-\mathrm{s}^{\mathrm{e}}\right]>0$.

The $\log$ linear equation (3a) can be rewritten as:

$$
s=1 /(1+\varepsilon) Z_{1}+\varepsilon /(1+\varepsilon) f
$$

An increase in a forward rate will cause spot exchange rate to appreciate when all other variables remain constant. An additional discussion regarding the prices can be incorporated into the first term, $\left(\mathrm{k}^{*}-\mathrm{k}\right)$ in $\mathrm{Z}_{1}$. Frenkel and Mussa (1985) allow the weighted average of the prices of traded and non-traded goods. This indicates that the domestic price index is given by the equation, $\mathrm{p}=\sigma \mathrm{p}_{\mathrm{T}}+(1-\sigma) \mathrm{p}_{\mathrm{NT}}$, and the foreign price index is given by the equation, $\mathrm{p}^{*}$ $=\sigma^{*} \mathrm{p}^{*} \mathrm{~T}+\left(1-\sigma^{*}\right) \mathrm{p}^{*} \mathrm{NT}$, where $\mathrm{pr}$ denotes the logarithm of the prices of internationally tradable goods, p $_{\mathrm{NT}}$ is the logarithm prices of non-tradables, $\sigma$ represents the weight of tradables, and $(1-\sigma)$ is the weight of non-tradable. If $\sigma=\sigma^{*}$ $=1$, then the price index will be based only on the tradable goods.

Assuming that $\sigma=\sigma^{*}$ for simplicity, the following equation is obtained:

$$
s=1 /(1+\varepsilon) Z_{2}+\varepsilon /(1+\varepsilon) f
$$

Where $\mathrm{Z}_{2}$ is $\left\{\left(\mathrm{p}^{*}-\mathrm{p}\right)+\lambda\left(\mathrm{m}-\mathrm{m}^{*}\right)+(1-\lambda)\left(\mathrm{m}-\mathrm{m}^{*}\right)+\mathrm{n}\left(\mathrm{y}^{*}-\mathrm{y}\right)\right\}$ and the price differential is $\left(\mathrm{p}^{*}-\mathrm{p}\right)=\sigma\left(\mathrm{p}^{*} \mathrm{~T}-\mathrm{p}_{\mathrm{T}}\right)+(1-\sigma)\left(\mathrm{p}_{\mathrm{NT}}^{*}-\mathrm{p}_{\mathrm{NT}}\right)$. Note that the prices of non-tradable goods tend to be higher than those of tradable goods in the capital-abundant rich nations, but the prices of the non-tradable goods are relatively lower in the poor labor-abundant countries because most of the non-tradable goods are services.

A modern exchange rate determination may include a dynamic linkage between the exchange rate and the current account of the international payment balance. Frankel (1985) discovered that the government deficit and the current account deficit tend to depreciate domestic currency as foreign debts increase. We assume that the asset differential, ( $\left.w^{*}-w\right)$, occurs when the accumulated currency holdings appear in a condition where $w$ indicates the domestic financial bonds owned by the domestic residents and $\mathrm{w}^{*}$ is the foreign assets owned by the domestic residents.

Accordingly, the equation (4a) will be expressed through:

$$
s=1 /(1+\varepsilon) Z_{3}+\varepsilon /(1+\varepsilon) f
$$


In the equation, $Z_{3}$ refers to $\left\{\left(\mathrm{p}^{*}-\mathrm{p}\right)-\left(\mathrm{w}^{*}-\mathrm{w}\right)+\lambda\left(\mathrm{m}-\mathrm{m}^{*}\right)+(1-\lambda)\left(\mathrm{m}-\mathrm{m}^{*}\right)+\right.$ $\left.n\left(y^{*}-y\right)\right\}$. Note that the spot exchange rate tends to decrease as a result of the increase in the net accumulated financial asset flows, which results when there is a surplus of the current account. If sterilization is available, then a central bank may perform a sterilized intervention by exchanging domestic bonds to foreign bonds. This will result in changes of foreign exchange values in terms of unchanged domestic credits in a domestic open market operation, so that it can attain its policy goals.

So far, we have reviewed the standard forms for long-run exchange rate models. The inclusion of international macroeconomic fundamentals in combination with nominal flexibilities as a determinant of the long-term exchange rate appears to be very useful. This implies that bilateral and trilateral exchange rates at the long run equilibrium could be identified by fundamental drivers. However, the interplay between the exchange rates and the macroeconomic fundamentals might be less straightforward in the short-run.

\section{SHORT-RUN FOREIGN EXCHANGE RATE}

The section reviews the current literature on market microstructures to introduce the exchange rate determination in the short-term. This model starts with several stylized facts. First, the current exchange rate is expected to exhibit a high frequency because the PPP does not hold and the exchange rate can overshoot. Second, the spot exchange rate is characterized by the changes in the expectations about the short-run events or by rumors. Finally, unpredictable events in the news often affect the changes in the spot exchange rate. In this manner, many studies note that the forward exchange rate or the random walk model may both be superior to other exchange rate forecasting models in their ability to capture the short-run exchange rate behavior.

In other words, macro fundamentals fail to clearly capture the key features of the high-frequency exchange rates. An explanation of the short-term exchange rate dynamics should consist of the macro fundamentals as well as the micro market structures as suggested by Taylor (1995). According o Sager and Taylor (2006), the forecasts of the fundamental-based exchange rate can be improved by either the behaviors of the market participants or the market structures.

The standard way of describing a short-run asset market is with the aid of the exchange rate-interest rate combination. For instance, an increase in money supply will lower the domestic interest rate and increase the foreign currency price and also increase the purchases of relatively attractive foreign assets. Alternatively, a domestic open market purchase may have a bigger effect on the domestic interest rate and a smaller effect on the exchange rate than the open market operation in foreign securities. This indicates that direct purchases 
of foreign bonds made by central banks can contribute to making the exchange rate price higher than the increase in the money supply. Also, the increase in the foreign bonds stock may result in a great effect on the exchange rate movement and no effect on the domestic interest rate given that a net increase in wealth achieved by privately accumulating savings is equivalent to the gain of foreign assets.

A currency flow model derived by Neumann (1984) explains the exchange rate in the short-run equilibrium. This model is consistent with the equation, $\mathrm{NV}=\mathrm{CA}+\mathrm{KA}$, where NV denotes the net demand of the foreign currency (net supply of domestic money in the foreign exchange market). CA is the surplus of the current account, $\mathrm{KA}$ is the surplus of the capital account, and the sum of $\{\mathrm{CA}+\mathrm{KA}\}$ denotes the net supply of the foreign currency (net demand of domestic money in the foreign exchange market). Note that the amount of foreign currency purchased is at the discretion of the central bank and this represents the NV, which is zero in complete floats. Furthermore, we assume that the foreign currency demand and supply are mostly focused on the role of particular market players or the trading process, in which the financial traders are speculators and the commercial traders are investors engaged in international trades.

Neumann's model is replaced by the model of Osler (2006) in parts. Then, the equilibrium demand condition is as follows: $\left\{\mathrm{N}_{\mathrm{ct}} \cdot \Delta \mathrm{Q}+\mathrm{N}_{\mathrm{ft}} \cdot \Delta \mathrm{K}\right\}=$ 0 . In this equation, the net flow demand sums to zero in the equilibrium. The second term, $\mathrm{N}_{\mathrm{ft}} \cdot \Delta \mathrm{K}$ describes the aggregate net financial demand in which $\mathrm{N}_{\mathrm{ft}}$ is the number of the financial trader and $\Delta \mathrm{K}$ is the change in the optimal position of representative speculator over time. The variable $\mathrm{K}$ represents the optimal position size of the domestic currency assets in terms of the foreign financial traders. Specially, the optimal position is specified as $\mathrm{K}=\left\{\left[\mathrm{i}-\left(\mathrm{s}^{\mathrm{e}}-\mathrm{s}\right)\right]\right.$ $\left.-\mathrm{i}^{*}\right\} /\{\theta \cdot \operatorname{var}(\mathrm{s})\}$, where $s$ is equal to the spot exchange rate, $s^{\mathrm{e}}$ is the expected exchange rate, $i$ the domestic interest rate, $i^{*}$ is the foreign interest rates, $\theta$ is the risk aversion degree, and $\operatorname{var}(\mathrm{s})$ is the variance of the exchange rate. All of the variables are logarithmic and are computed in units of the foreign currency.

Note that the optimal position size of the financial agent $(\mathrm{K})$ is positively related to the difference between the expected profits of the domestic assets (i) and the expected profits of the foreign currency assets $\left(i^{*}+\left(s^{e}-s\right)\right)$ when all other variables are constant. Also, note that it is negatively related to the risk aversion $(\Theta)$ and the dispersion of exchange rate $(\operatorname{var}(s))$. The first term of the equilibrium equation is $N_{c} \cdot \Delta Q$ and describes the aggregate net commercial demand in which $\mathrm{N}_{\mathrm{ct}}$ indicates the number of commercial traders and $\triangle \mathrm{Q}$ refers to the change in the optimal position of the representative investor over time. The variable $\mathrm{Q}$ represents the optimal position size of the net export from the viewpoint of the domestic commercial traders. It can be assumed that 
this optimal position is the certain value specified in the implicit function form of $\mathrm{Q}=\mathrm{f}\left(\left(\mathrm{s}+\mathrm{p}^{*}-\mathrm{p}\right)\right.$, $\left.\mathrm{y}\right)$, where $\left(\mathrm{s}+\mathrm{p}^{*}-\mathrm{p}\right)$ is the log real exchange rate and $\mathrm{y}$ is the log income.

Actually, the equation $\left\{\mathrm{N}_{\mathrm{ct}} \cdot \Delta \mathrm{Q}+\mathrm{N}_{\mathrm{ft}} \cdot \Delta \mathrm{K}\right\}=0$ represents a large portion of the financial capital movements and a relatively small share of the commercial trades in foreign currency flows. This also neglects any interventions that a government may have in the foreign exchange market. So, the net financial currency order flow may be inversely proportional to the net commercial currency order flow. The approach to adjusting the exchange rates by equilibrating international trades is a traditional and minor one because the prices of the goods adjust much slower than the prices of the financial assets.

By the way, in the microstructures of the foreign exchange market suggested by McGroarty et al. (2006), Osler (2006), and Sager and Taylor (2006), alternatively the foreign exchange trading mechanism or the order flows can aide in our understanding of the market practices and the interactions of the participants. The order contract flows of a foreign currency are the signed trading volumes in an interval of time in which the contracted buyer-initiated and the seller-initiated orders are between counterparties. In reality, these order flows convey individual expectations and there is little information that is available to the public. 5

For the description of connections between order flows and spot exchange rate, this paper introducesthe log linear equation of the short-run exchange rate change introduced by Evans and Lyons (2002b).

$$
\Delta s=\Delta r+\phi \cdot \Delta \mathbf{x}
$$

In a condition where $\Delta$ is equal to the sign of difference over time, $s$ is the spot exchange at the end of the day, $r$ is the common macroeconomic information increment, $\phi$ is the constant coefficient, and $x$ is the total order flow increments. Note that $\mathrm{x}$ is the sum of the inter-dealer trading orders that are in proportion to the number of customer trading orders in order to maintain equilibrium throughout the day. The equation (5) indicates that the exchange rate changes reflect both the changes in the public information and the changes in the order flow. Additionally, the changes in the nominal interest differential, $\Delta\left(\mathrm{i}-\mathrm{i}^{*}\right)$ would be used instead of $\Delta \mathrm{r}$ for estimation purposes. And note that a distinction between the trading rounds is excluded here.

Exchange rates would still be high frequency. Dealers drive bilateral and trilateral exchange rates to a point where it is equal to each other by exploiting an arbitrage opportunity. Furthermore, the micro-foundation theory would explain the temporal exchange rate behavior in other standpoints. First, the liquidity theory represents that the bid-ask spread is regarded as a transaction cost of liquid services and therefore, a rise of transaction cost will increase the spread. Second, the adversary theory suggests that the exchange rate volatility causes 
a spread risk to increase. The reduction in order flows will also widen the spread. Third, the inventory effect offers the same as the second case. Osler (2006) proves that the positive relation exists between the net order flows (currency buying orders minus the selling orders) and the currency prices. Finally, the information effect supports that order flows increase prices in the sense that order flows convey information about the exchange rate as stated by Osler (2006).

\section{FOREIGN EXCHANGE RATE EXPOSURES ON OPTIMIZATION}

This section analyzes the exchange rate's impact on the real economy. This paper offers a feasible optimization model in order to investigate how the exchange rate behaves with representative individuals and businesses. Considering three-dimensional frameworks allows for three tradable goods in the world where there are one home and two foreign nations. Each country produces single product, and has an infinitely-lived representative agent under the flexible exchange rates between the three types of currencies.

\section{Demand Behavior of Households}

We assume that a representative household has utility form from the level of consumption relative to exchange rate subsistence. She is assumed to take the instantaneous CES utility function from its expenditure and income. Also, suppose that the immortal household maximizes the welfare subject to a lifetime budget constraint, and discounts its future utility at a constant rate within a time preference of their choosing. The ability to have constant expected marginal utilities implies that consumers will be able to smooth their consumption over time. The homothetic utility function exhibits an invariant preference with respect to the monotonic transforms of utility.

Our intertemporal utility form between tradable goods is expressed in the following equation:

$$
\mathrm{U}\left(\mathrm{X}_{1}, \mathrm{X}_{2}, \mathrm{X}_{3}\right)=\sum_{\mathrm{t}=0}^{\infty} \beta^{\mathrm{t}}\left(\mathrm{a}_{1} \mathrm{X}_{1}{ }_{1}+\mathrm{a}_{2} \mathrm{X}_{2}{ }_{2}+\mathrm{a}_{3} \mathrm{X}_{3}\right)^{1 / \rho}
$$

In this equation, $\mathrm{U}($.$) indicates the utility function sign. The variable \mathrm{X}_{1}$ represents the home-produced products that domestic households consume and domestic producers export abroad. The variables $\mathrm{X}_{2}$ and $\mathrm{X}_{3}$ indicate foreign-produced goods. The parameter $\beta$ is the discount factor offering the same time preference to all of the countries, $a$ is the product preference-weighting fraction, and $\rho$ is the consumption adjustment for all of the countries, which indicates the constant elasticity of the consumer substitutions between the tradable goods. Specifically, the discount factor can take a value between 0 and 1 and $a_{1}+a_{2}+a_{3}=$ 
1 is the constraints on the preference weights. In the linear homogeneous CES utility function, the substitution elasticity is computed as $1 /(\rho-1)$ and we assume the condition of $0<\rho<1$ since the parameter $\rho$ varies between 0 and $\infty$. In addition, the CES function becomes the Cobb-Douglas function when $\rho=0$.

The behavior of consumers is better expressed by the inverse demand function than the direct demand function. The inverse demand function is described as the price as function of a bundle of goods in a competitive market. The necessary conditions for the utility maximization problem are given as $[\partial \mathrm{U}(\mathrm{X}) /$ $\left.\partial \mathrm{X}_{\mathrm{i}}-\lambda \mathrm{P}_{\mathrm{i}}=0\right]$ and $\left[\sum_{\mathrm{i}=1}{ }^{3} \mathrm{P}_{\mathrm{i}} \cdot \mathrm{X}_{\mathrm{i}}=\mathrm{M}\right]$, where $\lambda$ is the Lagrangian multiplier, $P_{i}$ is the price of good $i, X_{i}$ is the demand quantities of good $i$, and $M$ is the total expenditure. After arranging them, the indirect demand function may be expressed in the following equation, $\mathrm{P}_{\mathrm{i}}=\mathrm{P}_{\mathrm{i}}(\mathrm{X})=\left\{\left[\left(\partial \mathrm{U}(\mathrm{X}) / \partial \mathrm{X}_{\mathrm{i}}\right) \cdot \mathrm{M}\right] \div\right.$ $\left.\left[\sum_{\mathrm{i}=1}{ }^{3}\left(\partial \mathrm{U}(\mathrm{X}) / \partial \mathrm{X}_{\mathrm{i}}\right) \cdot \mathrm{X}_{\mathrm{i}}\right]\right\}$. Therefore, the equilibrium price vectors, $\mathrm{P}_{\mathrm{i}}$, can be expressed by the demand vectors, $\mathrm{X}$, for each period:

$$
\begin{aligned}
& P_{1}=P_{1}\left(X_{1}, X_{2}, X_{3}\right)=\left(a_{1} X_{1}{ }^{(\rho-1)} \cdot M\right) \div\left(a_{1} X_{1}{ }^{\rho}+a_{2} X_{2}{ }^{\rho}+a_{3} X_{3}{ }^{\rho}\right) \\
& P_{2}=P_{2}\left(X_{1}, X_{2}, X_{3}\right)=\left(a_{2} X_{2}{ }^{(\rho-1)} \cdot M\right) \div\left(a_{1} X_{1}{ }^{\rho}+a_{2} X_{2}{ }^{\rho}+a_{3} X_{3}{ }^{\rho}\right) \\
& P_{3}=P_{3}\left(X_{1}, X_{2}, X_{3}\right)=\left(a_{3} X_{3}{ }^{(\rho-1)} \cdot M\right) \div\left(a_{1} X_{1}{ }^{\rho}+a_{2} X_{2}{ }^{\rho}+a_{3} X_{3}{ }^{\rho}\right)
\end{aligned}
$$

In theses equations, $\mathrm{P}$ denotes the price of domestic good $\left(\mathrm{P}_{1}\right)$ and imported foreign goods $\left(\mathrm{P}_{2} a_{d} \mathrm{P}_{3}\right)$. The price function of $\mathrm{X}$ indicates that the quantity of the goods has an inverse relationship with its price.

Furthermore, all consumers are assumed to participate in each trading period under the same economic conditions. In the case of Obstfeld and Stockman (1985), the first order condition requires that the marginal rate of substitution between the domestic nation and the foreign nation are equal in their relative price. That is, $\mathrm{P} / \mathrm{S} \cdot \mathrm{P}^{*}=\mathrm{MU} / \mathrm{MU}^{*}$, where $\mathrm{P}$ represents the domestic price level, $\mathrm{P}^{*}$, the foreign price level, $\mathrm{S}$, the exchange rate, $\mathrm{MU}$, the domestic marginal utility, and $\mathrm{MU}^{*}$, the foreign marginal utility. The general price index is simply given by the price of the individual product that is produced by its own country in order to show the impact that the change in exchange rates has on the welfare of its consumers. Hence, the home marginal utility can be expressed as $\mathrm{MU}_{1}=\left(\mathrm{P}_{1} \cdot \mathrm{MU}_{2}\right) \div\left(\mathrm{P}_{2} \cdot \mathrm{S}_{12}\right)$, where $\mathrm{MU}_{1}$ is the value of the domestic marginal satisfaction, $\mathrm{MU}_{2}$ is the value of foreign nation 2's marginal satisfaction, and $S_{12}$ is the exchange rate between the home and foreign country 2. The home marginal utility can also be presented as $\mathrm{MU}_{1}=\left(\mathrm{P}_{1} \cdot \mathrm{MU}_{3}\right) \div\left(\mathrm{P}_{3} \cdot \mathrm{S}_{13}\right)$, where $\mathrm{MU}_{3}$ is the value of the foreign nation 3's marginal satisfaction and $\mathrm{S}_{13}$ is the exchange rate between the home and country 3 .

Together, (7a)-(7c) represents the home marginal utility equation:

$$
\begin{aligned}
& M_{1}=\left(a_{1} / a_{2}\right) \cdot\left(X_{1} / X_{2}\right)^{(\rho-1)} \cdot\left(M_{2} / S_{12}\right) \text { or } \\
& M U_{1}=\left(a_{1} / a_{3}\right) \cdot\left(X_{1} / X_{3}\right)^{(\rho-1)} \cdot\left(M_{3} / S_{13}\right)
\end{aligned}
$$


Under the present utility level, the simple measure of exchange rate exposure to a currency is $\mathrm{dMU} / \mathrm{dS}$, where $\mathrm{d}$ indicates the differential sign. The exchange rate exposure is obtained by differentiating equation (8) with respect to $\mathrm{S}$. This yields $\mathrm{dMU}_{1} / \mathrm{dS}_{12}=-\left(\mathrm{a}_{1} / \mathrm{a}_{2}\right) \cdot\left(\mathrm{X}_{1} / \mathrm{X}_{2}\right)^{(\rho-1)} \cdot\left(\mathrm{MU}_{2} /\left(\mathrm{S}_{12}\right)^{2}\right)<0$ and $\mathrm{dMU}_{1} / \mathrm{dS}_{13}$ $=-\left(a_{1} / a_{3}\right) \cdot\left(X_{1} / X_{3}\right)^{(p-1)} \cdot\left(\mathrm{MU}_{3} /\left(S_{13}\right)^{2}\right)<0$. A unit change in the exchange rate leads to a negative effect of the marginal utility. The size of the exchange rate exposure will be as much as the foreign marginal utility divided by the squared exchange rate if $a_{1}=a_{2}=a_{3}$ and $X_{1}=X_{2}=X_{3}$ are held. Otherwise, the exchange rate exposure size is positively dependent on $\left(a_{1} / a_{2}\right)$ or $\left(a_{1} / a_{3}\right)$, $\left(\mathrm{X}_{1} / \mathrm{X}_{2}\right)$ or $\left(\mathrm{X}_{1} / \mathrm{X}_{3}\right)$, and the $\rho$-value as long as the value of the foreign marginal utility is constant.

Finally, the rearranged equation (8) for the equilibrated exchange rate is as follow:

$$
\begin{aligned}
& \mathrm{S}_{12}=\left(\mathrm{a}_{1} / \mathrm{a}_{2}\right) \cdot\left(\mathrm{X}_{1} / \mathrm{X}_{2}\right)^{(\rho-1)} \cdot\left(\mathrm{MU}_{2} / \mathrm{MU}_{1}\right) \text { and } \\
& \mathrm{S}_{13}=\left(\mathrm{a}_{1} / \mathrm{a}_{3}\right) \cdot\left(\mathrm{X}_{1} / \mathrm{X}_{3}\right)^{(\rho-1)} \cdot\left(\mathrm{MU}_{3} / \mathrm{MU}_{1}\right)
\end{aligned}
$$

Equation (9) indicates that the exchange rate appreciates when both foreign marginal utility and oversea produced products increase. Whereas the exchange rate depreciates with the rise of the amount of domestically produced products. Specially, the marginal utility could be expected to reflect a present marginal utility in the short run or a total sum of current marginal utility and expected utility in the long run.

\section{Supply Behavior of Firms}

A producer hires inputs in order to produce outputs given available production technology. The representative firm maximizes the profit level each period. The firm behaves competitively and accepts prices as specified. The assumption is also made that the home and foreign countries are incompletely specialized in the production of their own products. Then, the profit of the domestic firm is represented by the following equations:

$$
\pi_{1}=P_{1} X_{1}{ }^{d}+S_{12} P_{1}^{f 2} X_{1}^{f}+S_{13} P_{1}{ }^{f 3} X_{1}{ }^{f}-C_{1} X_{1}
$$

Here, the firm faces the production constraint such that $\mathrm{X}_{1}=\mathrm{X}_{1}{ }^{\mathrm{d}}+\mathrm{X}_{1}{ }^{\mathrm{f}}$, where $\mathrm{X}_{1}$ is the home produced goods, $\mathrm{X}_{1}{ }^{\mathrm{d}}$ is the home produced and sold goods, and $\mathrm{X}_{1}{ }^{\mathrm{f}}$ is the home produced and exported goods. All of the products are homogeneous. This is similar with the model that Bodnar et al. (2002) describes. Further, an export price is assumed to be inflated such that $\mathrm{P}_{1}{ }^{\mathrm{f}}=$ $\left(\mathrm{P}_{1} / \mathrm{S}_{12}\right)+t_{2}$ and $\mathrm{P}_{1}{ }^{\mathrm{f}}=\left(\mathrm{P}_{1} / \mathrm{S}_{13}\right)+t_{3}$, where $\mathrm{P}_{1}{ }^{\mathrm{f}}$ is the price of the goods in country 2 's currency, $P_{1}{ }^{f 3}$ is the price of the goods in country 3 's currency, 
$t_{2}$ is an additional positive transaction cost involved in exporting the goods to country 2 in their currency, and $t_{3}$ is the additional expenses to country 3. Finally, $C_{1}$ denotes the marginal cost in its home currency. In addition, the profits of the foreign firms, $\pi_{2}$ and $\pi_{3}$, can be derived in the same way.

Moreover, the profit of the domestic firm is re-expressed with respect to $P_{1}$ and $X_{1}$ such that $\pi_{1}=P_{1} \cdot\left(X_{1}-X_{1}{ }^{f}\right)+\left(P_{1}+S_{12} t_{2}\right) \cdot\left(X_{1}-X_{1}{ }^{d}\right)+\left(P_{1}+S_{13} t_{3}\right) \cdot\left(X_{1}\right.$ $\left.-X_{1}{ }^{\phi}\right)-C_{1} X_{1}$. Incorporating this with equation (7a) will yield, $\pi_{1}=\left\{\left(X_{1}-X_{1}^{f}\right) \cdot\left(a_{1} X_{1}^{(0-}\right.\right.$ 1) $\left.\cdot M) \div\left(a_{1} X_{1}{ }^{\rho}+a_{2} X_{2}{ }^{\rho}+a_{3} X_{3}{ }^{\rho}\right)\right]+\left[\left(X_{1}-X_{1}{ }^{d}\right) \cdot\left(a_{1} X_{1}^{(\rho-1)} \cdot M\right) \div\left(a_{1} X_{1}^{\rho}+a_{2} X_{2}{ }^{\rho}\right.\right.$ $\left.\left.+a_{3} X_{3}{ }^{\rho}\right)\right]+\left[S_{12} t_{2} \cdot\left(X_{1}-X_{1}{ }^{d}\right)\right]+\left[\left(X_{1}-X_{1}{ }^{d}\right) \cdot\left(a_{1} X_{1}{ }^{(\rho-1)} \cdot M\right) \div\left(a_{1} X_{1}{ }^{\rho}+a_{2} X_{2}{ }^{\rho}\right.\right.$ $\left.\left.+a_{3} X_{3}{ }^{\rho}\right)\right]+\left[S_{13} t_{3} \cdot\left(X_{1}-X_{1}^{d}\right)\right]-C_{1} X_{1}$. Thus, the marginal profit of the firm $\left(\mathrm{MR}_{1}\right)$ is obtained by $\mathrm{d} \pi_{1} / \mathrm{dX}_{1}$. This computed marginal profit may be equal to or unequal to the marginal cost, $\mathrm{C}_{1}$, since the exporting price may be more than the marginal cost specified. The exchange rate exposure on the marginal profit is obtained by differentiating the $\mathrm{MR}_{1}$ equation with respect to $\mathrm{S}$. That is, $d \mathrm{MR}_{1} / \mathrm{dS}_{12}=\mathrm{t}_{2}>0$ and $\mathrm{dMR}_{1} / \mathrm{dS}_{13}=\mathrm{t}_{3}>0$. A unit change in the exchange rate results in a proportional change in the marginal profit. The size of the exchange rate exposure represents the absolute value of the additional transaction costs in addition to the primitive cost associated with trading with foreign countries in its own currency.

At the end, we rearrange the equilibrated exchange rate as follows:

$$
\begin{aligned}
& S_{12}=P_{1} /\left(P_{1}{ }^{f 2}+t_{2}\right) \text { and } \\
& S_{13}=P_{1} /\left(P_{1}{ }^{f 3}+t_{3}\right)
\end{aligned}
$$

Equation (11) indicates that the exchange rate appreciates as both foreign sale prices and additional costs in foreign currencies decrease. Whereas the exchange rate appreciates as the domestic product rises. Specially, the exchange rates are expected to be affected by additional costs only in the short run while the exchange rates could be influenced by prices and additional costs in the long run.

\section{Feasible Results}

This section introduces the logical relationship to show the readers that the previous discussions and arguments are feasible. We summarized the short empirical findings. In particular, the consensus statistic estimates are used to provide a comprehensive summary. First, the long-run foreign exchange trading may represent currency position for weeks, months, and years to capture the long-term trends. Here, the monthly spot exchange rates for the long-term prices are examined from January 1, 2000 through September 1, 2007.6 Second, the daily spot rates, which are the assumptive equivalent to the short-term prices, are 
investigated from January 2, 2003 through October 16, 2007.7 The short term position may stand for durations ranging from a few minutes or a few hours to a day or a few days.

The exchange rates dataset of the global dealer spot electronic trading system are adopted in order to examine the exchange rate fluctuation. All of the trades on this system are executed by electronic bilateral conversations between quoting and calling dealers. And the dealers that act as global mercantile banks can determine the lead prices so that it reflects the prices set by both the local dealers and customers such as fund managers, corporations, and hedge funds.

The foreign exchange rates used in this paper are ten currencies: the Canadian dollar (CAD), the Japanese yen (JPY), the Korean won (KRW), the Australian dollar (AUD), the European euro (EUR), the British pound (GBP), the Mexican peso $(\mathrm{MXN})$, the Singapore dollar (SGD), the Thailand Baht (THB), and the Taiwanese dollar (TWD). The exchange rates used in this study are quoted in terms of the foreign currency per U.S. dollar (USD) ${ }^{8}$

\section{Table 1. Movements of Foreign Exchange Rate}

\begin{tabular}{|c|c|c|c|c|}
\hline & Correlating & Surprise & Volatility & Currency Substitute Stability \\
\hline \multicolumn{5}{|c|}{ Long-run duration } \\
\hline CAD & $-0.8 \%$ & 0.00 & $2.2 \%$ & 7.71 \\
\hline JPY & $-6.3 \%$ & - & $249.4 \%$ & 16.39 \\
\hline KRW & $-1.3 \%$ & - & $2075.8 \%$ & 8.89 \\
\hline AUD & $-1.2 \%$ & - & $1.7 \%$ & 6.12 \\
\hline EUR & $-1.1 \%$ & - & $2.5 \%$ & 6.58 \\
\hline GBP & $-1.5 \%$ & - & $3.3 \%$ & 8.89 \\
\hline MXN & $-2.5 \%$ & - & $17.4 \%$ & 13.26 \\
\hline SGD & $-2.1 \%$ & - & $1.8 \%$ & 19.05 \\
\hline THB & $-2.0 \%$ & - & $67.9 \%$ & 11.79 \\
\hline TWD & $-4.7 \%$ & - & $28.3 \%$ & 26.45 \\
\hline \multicolumn{5}{|c|}{ Short-run duration } \\
\hline CAD & $-0.1 \%$ & $0.4 \%$ & $0.6 \%$ & 10.17 \\
\hline JPY & $-0.7 \%$ & $-10.9 \%$ & $63.6 \%$ & 20.99 \\
\hline KRW & $-0.1 \%$ & $197.4 \%$ & $460.3 \%$ & 10.02 \\
\hline AUD & $-0.3 \%$ & $-0.2 \%$ & $0.5 \%$ & 11.80 \\
\hline EUR & $-0.4 \%$ & $-0.4 \%$ & $0.7 \%$ & 15.49 \\
\hline GBP & $-0.3 \%$ & $-0.4 \%$ & $0.9 \%$ & 14.78 \\
\hline $\mathrm{MXN}$ & $-1.4 \%$ & $-1.6 \%$ & $4.9 \%$ & 37.25 \\
\hline SGD & $-0.2 \%$ & $0.2 \%$ & $0.5 \%$ & 20.82 \\
\hline THB & $-0.1 \%$ & $4.8 \%$ & $16.4 \%$ & 11.93 \\
\hline TWD & $-0.4 \%$ & $-2.5 \%$ & $8.9 \%$ & 34.17 \\
\hline
\end{tabular}

NOTE: Note that daily data are noon buying rates (1,208 data points) and monthly data are average of daily figures ( 93 points), and (CAD $=1,728$ points, JPY $=1,728, \mathrm{KRW}=663$, AUD $=1,117, \mathrm{EUR}=1,741, \mathrm{GBP}=1,519, \mathrm{MXN}=728$, and $\mathrm{SGD}=1,665)$. 
The summary statistics of Table 1 provides the portraits of the foreign exchange dynamics. There are four measures to distinguish any patterns or characteristics from the exchange rate behaviors over time. First, the value of the price could indicate any bunches or discreteness over the price series. 9 The value of the surprise in the foreign exchange changes will explain the occurrences of temporal disequilibrium such as overshooting, gyrations, and misalignments. ${ }^{10}$ The disequilibrium may also occur by either the volatility or currency substitute stability. ${ }^{11}$

At first glance, our results appear to indicate the differential between the foreign exchange rate movements in the short-run and the long-run. First, all of the short-run prices exhibit correlation that is just slightly more than those of the long-run prices when measured in terms of a correlation coefficient equals 1. Second, the surprise of the KRW was found to arrive at about $200 \%$ exceptionally, the JPY approximately reached $-10.7 \%$, and the MXN approximately reached $-1.6 \%$. The CAD, AUD, EUR, GBP, and SGD currencies are all under $+-0.5 \%$. Third, the volatility is increasing with an accumulated uncertainty in all of the currencies analyzed. In our findings, the volatility in the long-run is much bigger than the volatility in the short-run. Significantly, the volatility seemed to overwhelm any margin trades. Surprisingly, the KRW exhibits an extremely higher degree of jumpiness. Finally, the currency substitute stability to the USD decreases due to the increased volatility over time in all currencies. The SGD, JPY, MXN, and GBP are feasibly stable although the CAD and MXN are expected to be very stable due to their linkage with the US dollar.

The foreign exchange market is an opaque and inefficient financial mechanism. Of course, some believe that the foreign exchange market is transparent and efficient. This opacity may come from the lack of understanding that participants have regarding the price processing patterns with non-symmetric information, different responding speeds and so on. The inefficiency may be caused by forecasting error, risk premium, and more Given this reality, we argue that above the discrepancy between the short-run and the long-run exchange rate behaviors will result from a partially different adjustment of the arbitrage mechanism.

Table 2. Foreign Exchange Rate in Inter-Dealer Direct Market

\begin{tabular}{|c|c|c|c|c|}
\hline & Correlating & Surprise & Volatility & Mean Difference between Markets \\
\hline \multicolumn{5}{|c|}{ Short-run duration } \\
\hline CAD & $-0.1 \%$ & $0.4 \%$ & $0.6 \%$ & 0.00025 \\
\hline JPY & $-0.7 \%$ & $-10.8 \%$ & $65.2 \%$ & 0.00851 \\
\hline AUD & $-0.3 \%$ & $-0.2 \%$ & $0.5 \%$ & 0.00003 \\
\hline GBP & $-0.3 \%$ & $-0.4 \%$ & $0.9 \%$ & 0.00017 \\
\hline SGD & $-0.2 \%$ & $0.2 \%$ & $0.4 \%$ & -0.00015 \\
\hline
\end{tabular}

NOTE: Note that all data are the closed prices at the interdealer direct market (Daily data are 1,248 points). 
This partially adjusted mechanism can be regarded as a kind of market force order, in that both bilateral and trilateral exchange rates are identified simultaneously by fundamentals drivers at the long-run equilibrium, but by market structures drivers at the short-run equilibrium.

As shown, the foreign exchange market seems to be an interdealer market although the size and scope of the global foreign exchange market is not exactly known. Thus, the foreign exchange movements through the inter-dealer direct market needs to be reviewed.

First, Table 2 indicates that the short-run correlating is the same as Table 1. Second, the surprise is found to have no differences with Table 1 . The volatility is almost equal to that of Table 1 . Finally, the sample average difference seems to be not significant in the short-run: CAD $=2.5$ pips, JPY $=85.1$ pips, AUD $=0.3$ pips, $\mathrm{GBP}=1.7 \mathrm{pips}$, and SGD $=-1.5$ pips. This implies that there is no large discrepancy between the non-direct and the direct markets except a temporal particular case.

\section{CONCLUSIONS}

The arbitrage mechanism is the exact means by which the foreign exchange market functions. An arbitrage confirms that bilateral exchange rate is the same as one common currency side of trilateral rates at the equilibrium. The present foreign exchange market systems, however, are imperfect. Further improvement is required to have the market function more efficiently.

In this sense, the study reviews the literature advances of the exchange rate per long-run and short-run duration. And we develop desirable attainments on the optimality conditions regarding the exchange rate effects on the economy. Also, a large number of exchange rate series are tested to identify any behaviors in the long run and the short run. We discover that all of the currencies exhibit slightly both decreases in correlation and volatility increases with accumulated uncertainty. Particularly, the volatility of the KRW and JPY are too higher.

Above all, a discrepancy between the short-run and long-run exchange rates appears to indicate a significant spread in their behavior. This may be caused by partially different adjustment of the arbitrage mechanism as a kind of market force order between the short-run and the long-run. Additionally, highly surprising or volatility situation will lead to a smaller yield of carry trades and a decrease in roll-over transactions.

\section{REFERENCES}

Bodnar, G. M., Dumas, B., and R. C. Marston. 2002. Pass-through and exposure. 
Journal of Finance 1: 199-231.

Evans, M. D. D. and R. K. Lyons. 2002. Order flow and exchange rate dynamics. Journal of Political Economy 110: 170-180.

Frankel, J. A. 1985. The dazzling dollar. Brookings Papers on Economic Activity 1: $199-217$.

Frenkel J. A. and M. L. Mussa. 1985. Asset markets, exchange rates and the balance of payment. Handbook of International Economics 2(14), edited by R. W. Jones and P. B. Kenen.

He, Y. and S. C. Sharma. 1997. Currency substitution and exchange rate determination. Applied Financial Economics 7: 327-336.

Ho, T. W. 2004. The foreign exchange exposure of capital structure: the 1997 Asian crises revisited. Applied Financial Economics 14: 497-505.

Kingston, G. and M. Melecky. 2007. Currency preferences and the Australian dollar. Journal of International Money and Finance 26: 454-467.

Levich, R. M. 1985. Empirical studies of exchange rates: Price behavior, rate determination and market efficiency. Handbook of International Economics 2(19), edited by R. W. Jones and P. B. Kenen.

McGroarty, F., Gwilym, O., and S. Thomas. 2006. Microstructure effects, bid-ask spreads and volatility in the spot foreign exchange market pre and post-EMU. Global Finance Journal 17: 23-49.

Muller, A. and W. F. C. Verschoor. 2007. Asian foreign exchange risk exposure. Journal of Japanese International Economies 21: 16-37.

Neumann, M. J. M. 1984. Intervention in the Mark/Dollar market: the authorities' reaction function. Journal of International Money and Finance 3: 223-239.

Obstfeld, M. and A. C. Stockman. 1985. Exchange-rate dynamics. Handbook of International Economics 2(18), edited by R. W. Jones and P. B. Kenen.

Osler, C. L. 2006. Macro lessons from microstructure. International Journal of Finance and Economics 11: 55-80.

Sager, M. J. and M. P. Taylor. 2006. Under the microscope: The structure of the foreign exchange market. International Journal of Finance and Economics 11: 81-95.

Taylor, M. P. 1995. The economics of exchange rates. Journal of Economic Literature.

\section{ENDNOTES}

'The largest global interdealer dealing systems are Reuters D3000 and Electronic Broking System (EBS).

2 The evidence may be consistent with the fact that the exchange rate exhibits high-volatility, overshooting, gyration, misalignment, risk premia, forecasting error, incomplete price managing process, asymmetric information, heterogeneous opportunity, etc.

${ }^{3}$ Similarly, the equilibrium approach assumes that the relationships among the exchange rate, interest rate, and price are placed at the market clearing equilibrium in order to allow for changes in the exchange rate to occur in part by preference or because of technology changes.

${ }^{4}$ Ho (2004) mentions that the foreign exchange risk exposure is represented by the sensitivity of 
changes in currency values of assets or liabilities, while the foreign exchange risk is computed by the second moments of the exchange rate variation. Muller and Verschoor (2007) determined that active global firms in Asia are highly exposed to foreign exchange risk because of their attachment to either the US dollar or the Japanese yen.

5 In the micro sense in that asymmetric information, diverse opportunities, various expectations, and discriminal reaction velocity to innovation may exist among a group of heterogeneous dealing agents.

${ }^{6}$ Data source: Board of Governors of the Federal Reserve System. Note that monthly prices are averages of daily figures of noon buying rates in New York City for cable transfers payable in foreign currencies.

7 Data source: Board of Governors of the Federal Reserve System. Note that daily prices are noon buying rates in New York City for cable transfers payable in foreign currencies.

${ }^{8}$ The three currencies AUD, EUR, and GBP are exceptionally quoted in terms of USD per foreign currency.

9 Correlating is simply computed by determining the dynamic correlation coefficient between the present and previous prices.

${ }^{10}$ Surprising is calculated as the first difference of the FX minus the first difference of the FX in the long-run.

11 Volatility is measured in the standard error of the FX changes. Currency substitute stability is computed in the mean of the FX divided by its standard error. 